\title{
El patrimonio cultural desde una perspectiva interdisciplinar e interinstitucional: una apuesta pedagógica con miras a suscitar y fortalecer la identidad ${ }^{1}$
}

\author{
Cultural heritage from interdisciplinarity and \\ interinstitutionality: a pedagogical strategy \\ to strengthen identity \\ Cómo citar:
}

Jamaica, J. (2019). El patrimonio cultural desde la interdisciplinariedad e interinstitucionalidad: una apuesta pedagógica con miras a suscitar y fortalecer la identidad. Designia, 6(2), 117-147.

\begin{abstract}
${ }^{1}$ Esta investigación se desarrolló de manera independiente y se presentó como ponencia en el V Seminario Internacional: Gestión del Patrimonio Cultural, evento académico organizado por la Universidad de Boyacá. Además, en Tejiendo Memorias 2017, el pasado como lugar y como recurso: un diálogo interdisciplinar de la Universidad Externado de Colombia.

*Especialista en pedagogía y docencia universitaria de la Universidad La Gran Colombia, docente del Colegio Bilingüe Integral, integrante de Reactivo Colectivo e investigador independiente con énfasis en: patrimonio cultural y su gestión social, educación patrimonial, museología, cultura, violencia y paz, arte e historia.

E-mail: jeissonjamaica485@gmail.com ORCID: http://orcid.org/0000-0003-3566-3755
\end{abstract}

\section{Palabras clave:}

Educación patrimonial, historia y arte, patrimonio e identidad cultural, interdisciplinariedad e interinstitucionalidad, y museo.

\section{Key words:}

Heritage education, history and art, cultural heritage and identity, interdisciplinarity and interinstitutionality, and museum.

\section{Recibido: 01/09/2018}

Aceptado: 05/08/2019

\section{Resumen:}

Bogotá cuenta con una amplia y diversa oferta cultural, no obstante, los índices de la última Encuesta Bienal de Culturas (2015) señalan que la mayoría de los habitantes de la ciudad no hace uso de dicha oferta. Esta problemática alimenta y se alimenta de una falta de apropiación del Patrimonio Cultural (PC) material e inmaterial, a la vez que genera un desafío para las instituciones gubernamentales, el sector privado, la academia y las comunidades, entre otros actores, en términos del diseño, ejecución y constante seguimiento de estrategias que garanticen el acceso, difusión y disfrute de actividades, bienes, servicios y espacios culturales. 
A partir de la educación patrimonial, esta investigación busca generar un diálogo interdisciplinar e interinstitucional para abordar distintos momentos de nuestra historia por medio del arte, con el objetivo de demostrar el potencial que el aprovechamiento de la oferta cultural tiene para romper barreras entre disciplinas y para acercar al espectador a su pasado a través del PC. Para ello, este estudio asocia cuatro períodos históricos, cuatro museos y cuatro objetos. Se evidencia entonces la forma en que, a través de un enfoque interdisciplinar e interinstitucional, es posible hacer del arte y de la apropiación del PC herramientas para el abordaje de procesos y eventos históricos complejos atados a la construcción de la identidad en Colombia.

\section{Abstract:}

Bogota has a wide and diverse cultural offer, however, the indices of the last Biennial Survey of Cultures (2015) point out that most of the inhabitants of the city don't take advantage of this offer. This problem sustains on and sustains from a lack of appropriation of the tangible and intangible Cultural Heritage $(\mathrm{CH})$, while it generates a challenge for government institutions, the private sector, academics and communities, among other actors, in terms of design, execution and constant monitoring of strategies which guarantee access, dissemination and enjoyment of activities, goods, services and cultural spaces.

Based on heritage education, this research seeks to generate an interdisciplinary and inter-institutional dialogue to address different moments in our history through art, with the aim of demonstrating the potential that the use of cultural offer has to break down barriers between disciplines and to arouse a closer approach to the past through the $\mathrm{CH}$. To accomplish this, the research associates four historical periods, four museums and four objects. It demonstrates, through an interdisciplinary and inter-institutional approach, that's possible to use art and the $\mathrm{CH}$ appropriation as tools for addressing complex historical processes and events tied to the construction of identity in Colombia. 


\section{Patrimonio cultural: definición, clasificación y gestión}

Todo pueblo tiene el derecho y el deber de defender y preservar su patrimonio cultural, ya que las sociedades se reconocen a sí mismas a través de los valores en que encuentran fuente de inspiración creadora.

Durante el Romanticismo del siglo XIX surge por primera vez el concepto patrimonio cultural (PC), antecedido por el término patrimonio histórico, que nació en el siglo XVIII con la Revolución Francesa. A estos dos se añade el de bien cultural, gracias a la Convención de La Haya para la Protección de los Bienes Culturales en caso de Conflicto Armado (1954) de la Organización de las Naciones Unidades para la Educación, la Ciencia y la Cultura (UNESCO). Es así como se consolidó el concepto del PC, a raíz de movimientos sociopolíticos; sin embargo, es importante aclarar que es habitual referirse a estos tres términos como sinónimos (Pizano, Zuluaga \& Quiroga, 2010; Molano, 2007).

Según Therrien (1993, p. 2), el PC es "el conjunto de lugares, bienes, conocimientos, tradiciones y manifestaciones que forman parte de una nación, región o localidad, que por su interés deben preservarse para la comunidad". Por su parte, Molano lo define como "la historia entre la memoria individual y la colectiva, es parte de la transmisión de lo que ha sucedido en un territorio determinado" (2007, p. 77).

De igual manera, la legislación colombiana en la Ley General de Cultura entiende el PC como:

... todos los bienes materiales, las manifestaciones inmateriales, los productos y las representaciones de la cultura que son expresión de la nacionalidad colombiana, tales como la lengua castellana, las lenguas y dialectos de las comunidades indígenas, negras y creoles, la tradición, el conocimiento 


\begin{abstract}
ancestral, el paisaje cultural, las costumbres y los hábitos, así como los bienes materiales de naturaleza mueble e inmueble a los que se les atribuye, entre otros, especial interés histórico, artístico, científico, estético o simbólico en ámbitos como el plástico, arquitectónico, urbano, arqueológico, lingüístico, sonoro, musical, audiovisual, fílmico, testimonial, documental, literario, bibliográfico, museológico o antropológico (Ley 1185, 2008²).
\end{abstract}

Estas tres definiciones relacionan el PC con bienes muebles e inmuebles, con prácticas culturales de una sociedad, así como su quehacer, conocimientos, expresiones y costumbres en un territorio, con hechos históricos, tradiciones, entre otros. También se hace hincapié en la protección y preservación de los bienes culturales, en la medida en que estos son de interés colectivo. Asimismo, el PC se cataloga y se le atribuyen valores en diversos niveles.

En línea con las tres apreciaciones, el Ministerio de Cultura (citado por el Instituto Distrital de Patrimonio Cultural [IDPC], s.f.) clasifica el PC en material, inmaterial y natural: el primero, alude a bienes tangibles y los clasifica en inmuebles, que no pueden ser desplazados, y muebles, que sí son susceptible de desplazamiento; el segundo, se refiere a bienes intangibles, como las lenguas, prácticas, rituales, etc.; y el tercero, a formaciones geológicas, reservas o parques naturales, paisajes, etc., los cuales constituyen la biodiversidad.

Por lo tanto, el PC es y a su vez se crea, preserva, manifiesta y disfruta en numerosos espacios: galerías de arte, monumentos, centros históricos, plazas, bibliotecas, casas

${ }^{2}$ Modifica y adiciona la Ley General de Cultura (Ley 397 de 1997). de cultura, salas de cine, teatros, archivos, centros culturales, ferias, exposiciones, auditorios, parques escuelas de formación, obras de teatro, en la música, literatura y la danza, etc. En esta investigación se enfatiza en el patrimonio cultural preservado por museos. 
${ }^{3}$ Algunas definiciones del término patrimonio cultural son exclusivamente descriptivas, es imprescindible que el patrimonio también tenga un uso.

${ }^{4}$ El estudio no contempló la localidad de Sumapaz.

${ }^{5}$ De aquí en adelante, el uso de esta expresión referencia temporalmente el momento en que se hizo la encuesta, es decir, entre junio y septiembre de 2015
Respecto a estas definiciones y clasificaciones, según DeCarli (2018, p. 59), es imprescindible "elaborar proposiciones que se deriven de este concepto, así como su puesta en práctica" ${ }^{3}$, por lo cual el patrimonio es "el conjunto de bienes culturales y naturales, tangibles e intangibles, generados localmente, y que una generación hereda / transmite a la siguiente con el propósito de preservar, continuar y acrecentar dicha herencia" (DeCarli, 2006, citada por DeCarli, 2018, p. 59). Esta última definición amplía el concepto de patrimonio, ya que su gestión debe concebir estrategias que pongan valor en los bienes culturales, asignándoles así una función social; este es el modo más efectivo de preservarlos, según la autora. Para este estudio, la educación patrimonial es la herramienta que procura asignar dicha función social a las cuatro piezas preservadas por los museos.

En la ciudad de Bogotá, de acuerdo con el inventario del IDPC (Secretaría Distrital de Cultura, Recreación y Deporte [SCRD], 2016), se concentran 11404 Bienes de Interés Cultural (BIC). Debido a los numerosos bienes, servicios y espacios culturales con los cuales cuenta la capital, Bogotá se posiciona como un epicentro cultural en toda la región. Además de las cuantiosas actividades desarrolladas cada mes, cada semana y cada día, estos bienes, servicios, espacios y actividades son escenarios que, en sí mismos, propician la preservación, protección y difusión del patrimonio cultural, siendo puestos a disposición de los ciudadanos gracias a la gestión del sector privado y público, a las iniciativas de orden territorial, a la cooperación internacional, entre otras.

\section{El consumo cultural en Bogotá}

La última Encuesta Bienal de Culturas (SCRD - Observatorio de Culturas, 2016), contestada por 15674 participantes mayores de 13 años y residentes en la zona urbana estratificada de Bogotá (19 localidades"), "reconoce y examina la diversidad cultural de una ciudad en transformación permanente por sus propias dinámicas poblacionales y territoriales, por los influjos externos y por su extraordinaria capacidad de ser referencia, destino y centro de la nacionalidad" (párr. 2), y constituye una herramienta muy valiosa para estudiar y comprender la oferta cultural de la capital. A continuación, se presenta un breve panorama del sector con relación al consumo cultural.

Los índices de la encuesta, a partir de la vasta oferta cultural de la ciudad Bogotá, evidencian que en los últimos doce meses ${ }^{6}$ el $27.1 \%$ de la población asistió a teatro, el $20.4 \%$ a actividades de artes plásticas y visuales, el $24.9 \%$ a presentaciones de danza, el $41.5 \%$ a salas de cine y el $32.5 \%$ a presentaciones musicales. Además, el $8.5 \%$ de la 
población interpreta instrumentos, compone música o canta; el 5.7\% escribe novelas, poesía, ensayos, crónicas; el 7.3\% esculpe, teje o borda; el 9.5\% pinta, dibuja o toma fotografías; el $4.1 \%$ realiza instalaciones o escenografías; el $4.5 \%$ actúa en espectáculos escénicos y el $4.4 \%$ los dirige; y el $6.8 \%$ baila o crea coreografías.

En los últimos doce meses, el 51.8\% asistió por lo menos una vez al año a un recorrido por el centro histórico, el $50.4 \%$ visitó monumentos, el $50.2 \%$ fue a museos y el $34.4 \%$ a festivales populares. Respecto a equipamientos culturales, el $37.6 \%$ ha utilizado o visitado bibliotecas, el $20.1 \%$ casas de la cultura, el $20.3 \%$ museos, el $17.8 \%$ teatros, el $14.2 \%$ salas de exposición y galerías, y el $14.8 \%$ centros culturales. Asimismo, el $46.9 \%$ no se informa de la programación de actividades artísticas y culturales, y quienes si lo hacen, referencian como fuentes principalmente a la televisión (11.4\%), amigos o conocidos (9.7\%), y redes sociales $(7.9 \%)$.

El 82.2\% estima que la literatura es importante o muy importante en su vida, el $68.4 \%$ opina lo mismo del cine, el $77.5 \%$ respecto a la música, el $57.4 \%$ en cuanto a las artes plásticas y visuales, el $60.2 \%$ acerca de la danza y el $58.4 \%$ del teatro y el circo. Sin embargo, del $66.7 \%$ al $80.6 \%$ de los encuestados no recibieron ningún tipo de formación en las actividades anteriormente mencionadas. No obstante, el $63.2 \%$ considera fundamentales las clases de artes en los colegios, el 19\% como una forma de ocupar el tiempo libre y el 10.9\% como útiles, pero no imprescindibles. Respecto a las clases sobre patrimonio, el $70.7 \%$ las considera fundamentales para la formación de niños, niñas y jóvenes.

La lectura de estos resultados hace urgente el diseño, ejecución y seguimiento de estrategias que garanticen el acceso, difusión y disfrute de actividades, bienes, servicios y espacios culturales, lo que constituye, además, un reto para las instituciones gubernamentales, el sector privado, la academia y la comunidad, entre otros actores. De igual manera, se vislumbran varios de los desafíos del sector en términos de acceso y difusión de la cultura, políticas y derechos culturales, formación en áreas artísticas y culturales, percepción del arte y la cultura, entre otros aspectos. Este artículo pone a disposición una propuesta de orden conceptual como parte de la respuesta a esta problemática desde la óptica de la educación patrimonial. 
Dentro de los estudios referentes a educación patrimonial (EP), tenemos a García (2007) quien la define como una estrategia capaz de poner en valor la conservación, preservación y disfrute del patrimonio cultural y, "tiene como objeto de estudio diseñar estrategias y recursos educativos dirigidos a las personas que conviven con el PC".

Por su parte, Teixeira (2006) expresa que la EP "se configura como una praxis educativa y social que permite elaborar acciones pedagógicas privilegiando enfoques interdisciplinarios. Los bienes culturales permiten la integración de diferentes conocimientos que pretenden algo más que un estudio del pasado". Considera que la EP posibilita reconocer nuestra dimensión histórica, fortaleciendo así, nuestro compromiso con la sociedad.

Inclusive, la EP es una estrategia que se adapta tanto a la educación formal, como a la no formal e informal. Tal es el caso de Morán (2017), quien presenta una propuesta educativa en el ámbito de la educación informal sobre el Qhapaq Nan o Camino Inca, infraestructura prehispánica conformada hoy día por Perú, Ecuador, Colombia, Argentina, Chile y Bolivia, esta tiene una extensión aproximada de 60 000 kilómetros. La propuesta metodológica fue construida con las comunidades y se enmarcó en tres lineamientos: generar espacios de diálogo, desarrollar un proceso participativo de planificación e implementar un proceso de gestión concertada. De igual modo, se diseñaron cuatro módulos educativos regidos por un enfoque de derechos, interculturalidad y empoderamiento. Los principales resultados, fueron 10 emprendimientos replicados en 11 regiones como charlas en colegios, iniciativas de protección y conservación, formación de organizaciones juveniles locales, etc. Morán concibe que:

La propuesta educativa [...] no solo aporta en los participantes con respecto al proceso de autoconocimiento y empoderamiento, sino también a los gestores, quienes aprenden con los participantes de manera permanente, pueden de alguna forma evaluar su gestión con la identificación de las oportunidades y problemáticas, como también con los mapas parlantes y en los planes de trabajo que se diseñan (2017).

El proyecto MAC al cuadrado, desarrollado gracias a la alianza entre el Museo de Arte Contemporáneo y el Museo Colonial, con la participación de aproximadamente 450 estudiantes, incorporó la tecnología en la mediación de sus exposiciones. Se llevaron a cabo visitas comentadas y al final los participantes realizaron material audiovisual en relación con el contenido de los museos (UNIMINUTO, s.f.). Este tipo de estrategias no sólo emplean otro tipo de interacciones, sino que también se 
adecúan al contexto de la población. Asimismo, el departamento de acción educativa y cultural del Museo Nacional de Colombia además de contar con un equipo de trabajo interdisciplinar, también cuenta con estrategias educativas que no sólo establecen otros vínculos, sino que también se diseñan para otros públicos.

Respecto a la educación formal, García (2007), quien a partir de un proyecto educativo plantea la aproximación al PC desde el diseño curricular y 6 áreas de estudio en la educación básica venezolana. Su trabajo hace énfasis en niños de 7 a 13 años y "aborda el patrimonio en forma integral bajo una visión multidisciplinaria a través de los proyectos pedagógicos" (p. 4). García transversaliza el patrimonio al Currículo Básico Nacional en las demás asignaturas y contenidos, lo cual permite "trabajar la apropiación y sentido de pertenencia hacia el entorno natural y cultural de la localidad" Las seis áreas son: lengua y literatura, matemática, ciencias naturales, ciencias sociales, educación estética y educación física. La autora propone un esquema compuesto por cinco fases, las cuales pretenden que el docente y los alumnos descubran los valores patrimoniales de sus localidades e igualmente, se estimule la creación de una conciencia comunitaria encaminada al reconocimiento y preservación del PC.

En línea con Alfageme, M. y Martínez, N. (2007), los museos son alternativas distintas a la educación formal y hacen parte de nuestro entorno social. Son instituciones en donde se preserva, investiga y se comunica el patrimonio cultural. Hoy en día los museos cuentan con áreas educativas en donde se desarrollan talleres, visitadas guiadas, conferencias, entre otras actividades, que construyen puentes entre el patrimonio y los participantes, procurando que las personas se apropien de los bienes culturales que les pertenecen. El museo:

es una institución cultural que puede facilitar la comunicación con los usuarios y la información que ellos reciben [...] se están volviendo instrumentos sociales, se abren al público de una forma renovada e intentan mantener un diálogo con el visitante, haciéndole partícipe de lo que en él va aprendiendo (p. 13).

Estos estudios e iniciativas esbozados alrededor de la educación patrimonial están encaminados hacia el fortalecimiento de la identidad cultural, la cual "encierra un sentido de pertenencia a un grupo social con el cual se comparten rasgos culturales, como costumbres, valores y creencias" (Molano, 2007, p. 73). Además, la identidad "sólo es posible y puede manifestarse a partir del patrimonio cultural, que existe de antemano y su existencia es independiente de su reconocimiento o valoración" (Bákula, citada por Molano, 2007, p. 73 - 74). Siendo entonces la EP una estrategia que concatena disciplinas en pro de la preservación, difusión, activación, disfrute y apropiación del patrimonio Cultural y con la capacidad de influir en los índices de consumo cultural. 
Esta investigación pretende generar un diálogo interdisciplinar desde la educación patrimonial alrededor de tres pinturas y una cerámica. Estas obras están expuestas en cuatro museos de Bogotá. El propósito es proponer, desde la academia, una correlación capaz de suscitar y fortalecer la identidad cultural, abordando cuatro momentos, sacando partido del potencial artístico e histórico de los cuatro objetos. Con el fin de establecer dicha correlación interdisciplinar e interinstitucional se construyó el siguiente diagrama:

Se evidencia en el gráfico:
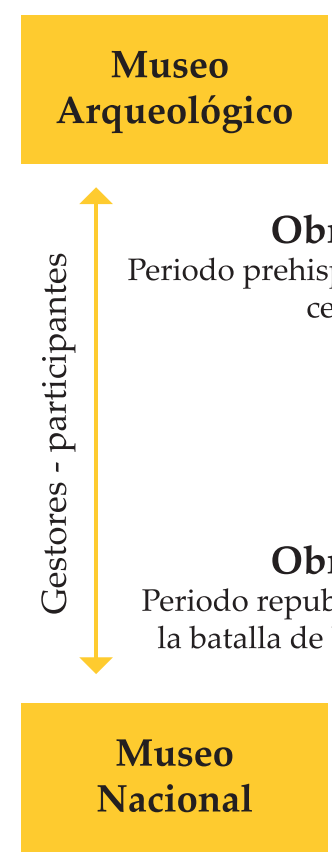

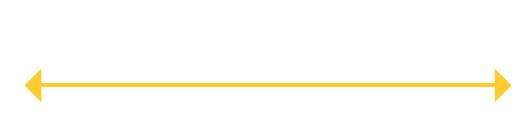

Obra \# 1: cerámica

Obra \# 3: anica

\section{Historia \\ Educación Patrimonial}

Arte

Obra \# 4:

Colombia contemporánea y el conflicto armado colombiano

\section{Museo \\ Colonial}

\section{Obra \# 2:}

Periodo colonial:

La orden religiosa de San Agustín

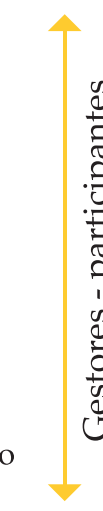


- La interinstitucionalidad: la relación entre cuatro espacios, Museo Arqueológico [MUSA] - Casa del Marqués de San Jorge, el Museo Colonial, el Museo Nacional de Colombia y el Museo Botero de Bogotá. Se considera imprescindible instalar y reforzar redes entre museos localizados en dos localidades aledañas, La Candelaria y Santa Fe, esto podría establecer enlaces entre las obras a partir de la historicidad, el arte y la educación. Son escasas las iniciativas que articulan espacios museísticos $\mathrm{y}$, muchas veces, estos salvaguardan objetos que dialogan perfectamente entre sí.

La interdisciplinariedad: como bien se ha dicho, la educación patrimonial posibilita la aproximación entre disciplinas, en este caso, el arte y la historia. La EP se convierte así, en la plataforma dialógica que se alimenta del patrimonio cultural preservado por instituciones museísticas.

Las cuatro obras: en primer lugar, se encuentra la cerámica de una figura antropomorfa de la cultura que estuvo localizada en el Cauca Medio, con la cual se pretende hacer alusión al periodo prehispánico. A continuación, la obra de Gregorio Vásquez de Arce y Ceballos, haciendo referencia al periodo colonial, con la llegada de una de las órdenes religiosas al país. Después, la pintura de Roberto Páramo Tirado con la batalla de Boyacá y el periodo republicano. Finalmente, el trabajo de Fernando Botero, quien representa en su obra la primera masacre perpetuada por paramilitares en el Caribe colombiano.

Gestores - participantes: se encuentran al principio y al final del gráfico porque hacen parte de un proceso de construcción colectiva que, si bien está estructurado, no se cierra a ser transformado. Se sugiere el enfoque pedagógico constructivista, en el cual, según Durán (2013), el sujeto cognitivo construye el conocimiento desde sus propias estructuras de aprendizaje, dándole un carácter reflexivo y cognoscitivo. Este sujeto toma un papel mucho más activo en contraste con otras posturas pedagógicas más tradicionales. El autor expresa

\footnotetext{
El ser humano construye y perfecciona progresivamente el conocimiento, y este proceso influye en la organización sociocultural; esta dinámica se da dentro de todo el despliegue de la experiencia individual-social. El ser humano incorpora, en la extensión compleja de su ser, los caracteres culturales antedichos y, a su vez, participa y contribuye en la configuración social constante de estos caracteres dentro de la experiencia social. (p. 5)
} 
La aproximación de la Educación Patrimonial al enfoque pedagógico constructivista propicia que los participantes vivan experiencias significativas en los museos, las cuales probablemente tendrán un mayor impacto. Por ello, en algunas instituciones museísticas se opta por los términos mediadores, intérpretes o comunicadores para referirse a quienes ejercen la labor de servir como puente entre los públicos y el patrimonio cultural, motivando un diálogo constante y vinculando el contexto y experiencia de los participantes con el mensaje que se desee transmitir. Asimismo, los museos con enfoque pedagógico constructivista le designan a sus públicos un rol mucho más activo.

\section{Cuatro museos, cuatro obras y cuatro momentos de nuestra historia}

Esta sección del artículo propone un recorrido por la cultura material, museos y periodos históricos. Inicialmente, se describe un contexto general; posteriormente, se aborda cada museo y pieza y, finalmente, se sugieren aproximaciones a cada objeto. En primer lugar, la cerámica que representa a la cultura que estuvo localizada desde el extremo noroccidental del departamento del Valle del Cauca hasta la región de Manizales, Caldas, incluyendo así a Risaralda, Quindío y la Figura Antropomorfa, haciendo alusión al periodo prehispánico, la cual está expuesta en el Museo Arqueológico (MUSA) Casa del Marqués de San Jorge. En segundo lugar, Gregorio Vásquez de Arce y Ceballos, reconocido exponente del arte religioso, y su obra San Agustín, la cual está exhibida en el Museo Colonial. En tercer lugar, el proceso de independencia y consolidación de la república, con Pedro Pascasio Martínez, ordenanza de Simón Bolívar, obra albergada en la exposición temporal del Museo de Nacional de Colombia: El reino frente al rey. Finalmente, el artista plástico Fernando Botero y la Masacre de Mejor Esquina, que da cuenta del conflicto armado en el país, en particular del paramilitarismo. 
${ }^{6}$ A pesar de que múltiples autores e instituciones todavía se refieren a esta zona arqueológica como Quimbaya, existen investigaciones recientes que han problematizado la delimitación en zonas arqueológicas de estas culturas. Por lo tanto, esta zona es entendida en este texto como el área que probablemente ocupó esa cultura prehispánica, bajo el supuesto de que tanto la delimitación tradicional como la que se hace en este documento podrían no estar completamente acertadas, según esas investigaciones.
Por ejemplo, la delimitación en zonas arqueológicas podría problematizarse en términos del discurso y la representación colonial según Franco (2017), en tanto podrían entenderse como formas de dar continuidad a narrativas arbitrarias y manifestaciones de la violencia simbólica y epistémica, atadas a las prácticas hegemónicas y coloniales.

\section{Periodo prehispánico: cerámica en el MUSA}

Quizá ningún otro pueblo o pueblos, como los de nuestro continente, se sirvieron de la cerámica para reflejar su progreso material y espiritual. Esta ha sido nuestra fortuna, ya que a través de esta variada y hermosa cerámica indígena, se nos revela la historia misma de su saber utilitario y cultural.

Arango (1979)

La cultura prehispánica probablemente estuvo localizada en la zona arqueológica que comprende desde el extremo noroccidental del departamento del Valle del Cauca hasta la región de Manizales en Caldas, incluyendo así, a Risaralda y Quindío $^{6}$.Se considera que su área de influencia abarcó no menos de 5000 kilómetros cuadrados. Poblaron la región desde el siglo I al VII después de Cristo, y con la llegada de España dejaron de existir rápidamente. Siempre se destacaron por su destreza en la orfebrería y la alfarería. Incluso, hoy día se sitúan entre los primeros en toda América prehispánica por la variedad, cantidad y calidad de su orfebrería (Museo Arqueológico [MUSA], 2006; Arango, 1979).

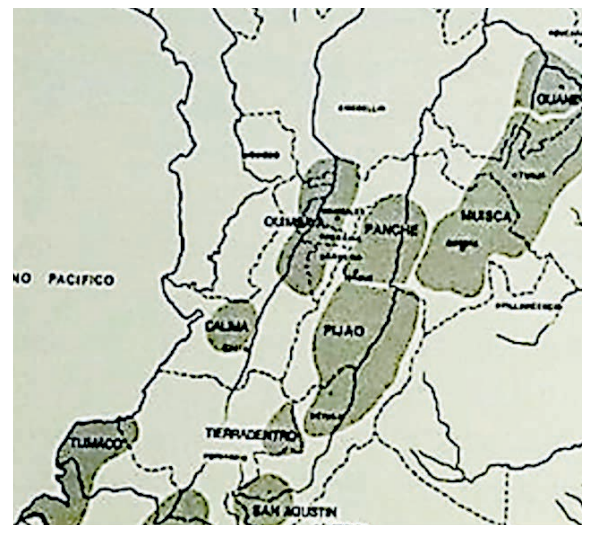

Figura 2. Zonas Arqueológicas Fuente: Arango (1979, p. 10). 
${ }^{7}$ Con formas alusivas a plantas.

${ }^{8}$ Con formas alusivas a personas.

${ }^{9}$ Con formas alusivas a animales.

${ }^{10}$ Jorge Lozano de Peralta.
En el campo de la cerámica, sobresalen sus tazas, copas, ánforas, alcarrazas, husos, pitos, entre otros, las cuales se usaban en quehaceres domésticos, como objetos decorativos, en ceremonias, ritos y otras manifestaciones de culto religioso. Sus piezas se distinguen por las interpretaciones fitomorfas ${ }^{7}$, antropomorfas ${ }^{8}$ y zoomorfas 9 . Para la elaboración de sus piezas usaban barro, arcilla o greda, materiales que posteriormente preparaban con gran habilidad para garantizar su durabilidad, y por otro lado, mostrar su realismo y belleza. Su estilo se caracteriza por el modelado de las piezas, generalmente en barro fino; el cubrimiento con engobe, comúnmente de color ocre, rojizo o amarillo pálido. Usaban, además, los colores negro, blanco y rojo para decorar. Respecto a la ornamentación, esta consiste en dibujos incisos, adicionando cordones de arcilla, con los cuales dibujan animales o delinean rostros humanos. Los dibujos forman también, triángulos, círculos, espirales, rombos, líneas cruzadas, etc. (Arango, 1979).

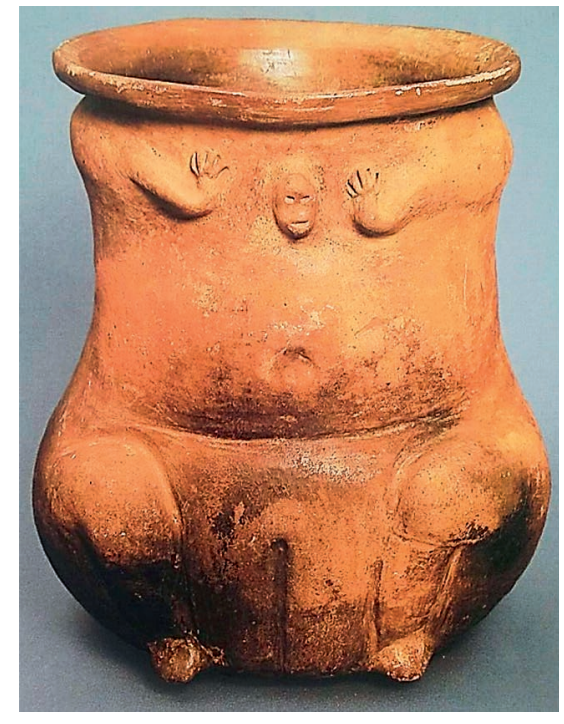

Figura 3. Urna cilíndrica de entierro secundario Fuente: MUSA (2006, p. 31).

Ahora bien, para este estudio, la pieza seleccionada se encuentra expuesta en el Museo Arqueológico; este abrió sus puertas en 1973, su sede fue la antigua casona que le perteneció al Marqués de San Jorge ${ }^{10}$. El museo alberga una de las colecciones de cerámica prehispánica más grande del país, además de una muestra colonial. A la fecha, el Museo cuenta con aproximadamente 15.000 piezas arqueológicas (Fondo de Promoción de la Cultura del Banco Popular, 1993). 
La pieza (figura 4) se denomina Figura antropomorfa, la cual es hueca y fue elaborada en un barro muy bien seleccionado. Tiene una abertura en su cabeza, aspecto por el cual recibe el nombre de gazofilacia o alcancía, ya que estas, al parecer, se usaban para depositar ofrendas a los dioses. Tiene pintura negativa en negro, rojo y blanco, formando triángulos, dos rectángulos ${ }^{11}$ y líneas que se cruzan. Algunas de estas figuras están sentadas, con las piernas cruzadas, en posición de loto, o como sugiere Arango, en posición budista, en este caso, con las manos sobre las rodillas. Tiene la cabeza alargada y puntiaguda en ambos costados. $\mathrm{La}$ figura tiene un cordoncillo que le rodea la cabeza, este podría significar un halo, es decir, un símbolo distintivo.

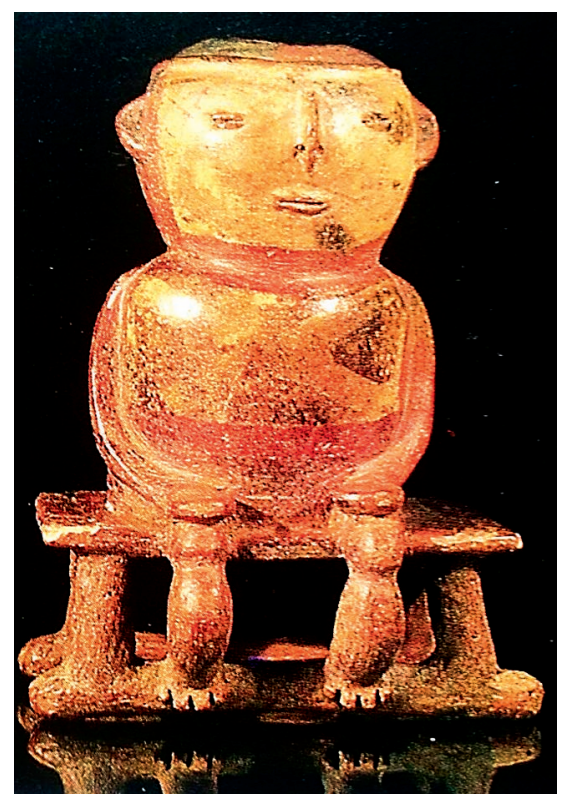

Figura 4. Figura antropomorfa Fuente: MUSA (2006, p. 76).

En sus pantorrillas tiene incisiones, las cuales "imitan pulseras o bien los cordones de chaquiras que los nativos ataban en [...] partes del cuerpo [probablemente] para realzar la belleza física [...] las partes de los brazos y piernas que quedaban aprisionadas entre esas ligaduras son abultadas" (Arango, 1979, p. 37). El personaje está sentado sobre un banco de la época, "un asiento amplio y plano con cuatro

${ }^{11}$ Uno en la cara y otro en el pecho. patas unidas por dos travesaños" (Fondo de Promoción de la Cultura del Banco Popular, 1990, p. 87). 
${ }^{12}$ Piezas con características similares podrían representar caciques.
Desde una perspectiva histórica, la Figura Antropomorfa nos permite abordar algunos aspectos del periodo pre-colonial. En primer lugar, según Rojas (1979), la ocupación, la migración y la llegada de estos pobladores desde el norte al territorio, "cuando fueron desalojados de sus dominios por el poderoso cacique Irrúa. En vista de esto resolvieron buscar nuevas tierras más hacia el sur". Esta cultura tuvo dos ocupaciones, la primera, caracterizada por grandes agricultores; la segunda, por indígenas sobresalientes en la orfebrería y alfarería.

Asimismo, la pieza posibilita introducir el cacicazgo ${ }^{12}$, forma de gobierno predominante. En aquella época existían varios caciques quienes tenían completa autonomía entre sí; se reunían primordialmente en caso de amenaza por parte de un enemigo en común, conformando así, juntas de guerra. El cacicazgo era heredado por el hijo y si este faltara, por el sobrino o hijo de la hermana. Los caciques lucían grandes cantidades de oro, tal es el caso del cacique Tucurumbi, quien bebía chicha en grandes vasijas de oro. Estos adornos y riquezas eran usados únicamente por los señores y su familia, lo cual denota diferenciación social. Las ceremonias y fiestas periódicas fortalecían los lazos de las comunidades, celebrando además juegos y festejos donde cantaban acerca de sucesos cotidianos o hechos importantes de sus antepasados (Rojas, 1979). De igual manera, la figura tiene un alto potencial estético, pues es posible aproximarse a la pintura corporal y a la vestimenta indígena prehispánica. 


\title{
Periodo colonial: Gregorio Vásquez de Arce y Ceballos en el Museo Colonial
}

\author{
El pintor más prolífico y el más controvertido de cuantos \\ hubo en Santa Fé en el siglo XVII. \\ Toquica, et al. (2008)
}

Según Ocampo (2017), en el periodo de europeización mundial, España fue el país representante de la religión católica y la cabecilla del orden hispánico. Tenía el objetivo de consolidar un gran imperio de ultramar por medio de un camino político-religioso. Esto pretendía enlazar el Estado español y la Iglesia católica: "lo cual se proyectó en las políticas de evangelización y organización eclesiástica en Hispanoamérica". En sus políticas de conquista espiritual, España auspició el Patronato Regio, a través del cual asumió la dirección de la acción misional en el nuevo mundo". Además, de acuerdo al autor, en la acción evangelizadora del siglo XVI prevalecieron las comunidades religiosas, principalmente las órdenes mendicantes: dominicos, franciscanos, agustinos, entre otros. Estas órdenes imponen "la pobreza de los religiosos y de los conventos, y cuyo sostenimiento debe basarse en la limosna de los fieles". La Corona española estimaba que las órdenes eran las más organizadas en sus objetivos evangelizadores.

Para referenciar este momento histórico, se cita el Museo Colonial, el cual se encuentra en la localidad de La Candelaria. Su sede es La casa de las aulas, construida a principios del siglo XVII. El Museo se inauguró el 6 de agosto de 1942, durante la presidencia de Eduardo Santos (Banco de la República, 2001).

En el Museo Colonial se encuentra la obra San Agustín (figura 5), pintada por Gregorio Vásquez de Arce y Ceballos. Según Toquica, et al. (2008) fue un criollo que marcó el comienzo de la memoria cultural neogranadina, su técnica tuvo elementos de orden local y global. Sin embargo, su forma de trabajo se acera más a la de un pintor europeo. Sus pinturas "representaban un discurso de valores que respondían a la estrategia católica de incentivar un mensaje cristiano dentro de los márgenes del dogma y la doctrina" (p. 35). Su trabajo fue el resultado de encargos, por parte de órdenes religiosas, devociones privadas, donantes, entre otras. 


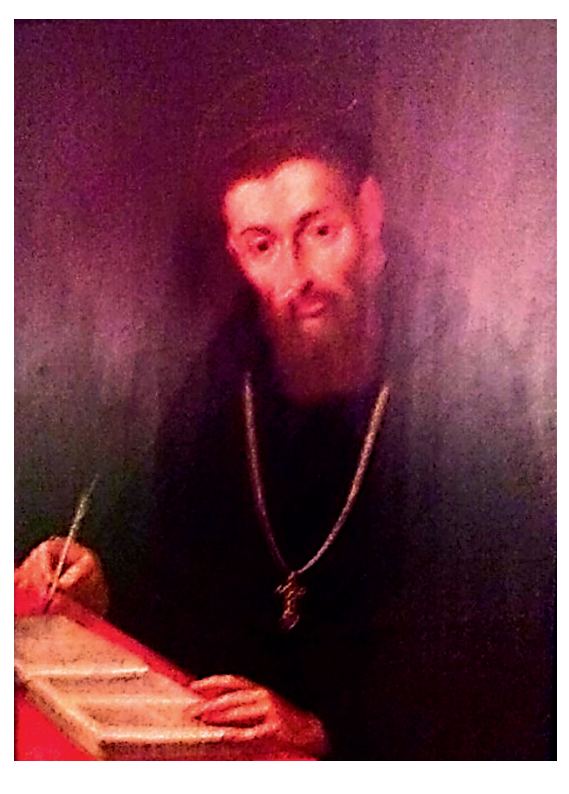

Figura 5. San Agustín Gregorio Vásquez de Arce y Ceballos (atribuida) Óleo sobre tela. Siglo XVII Museo de Arte Colonial.

El análisis de la obra permite mencionar la llegada a Bogotá, desde hace más de 400 años, de una orden mendicante: los frailes agustinos. En la carrera séptima con calle séptima está emplazado el templo de San Agustín como testimonio de la presencia de la orden en el Nuevo Reino de Granada. Su representante nació en Tagaste, norte de África, en el año 354, era de familia romana. Fue filósofo, teólogo y pensador fundamental del cristianismo. San Agustín murió en Hipona, Argelia en 430. La orden de ermitaños de San Agustín, se consolidó durante la Edad Media en abril de 1256, como resultado de la unión de varias congregaciones agustinas conformadas por monjes alojados en diferentes conventos, quienes se dedicaban al estudio de las obras de San Agustín. Su misión principal fue la de santificar y enseñar (Museo Nacional de Colombia, et al., 2002). No obstante, en el marco de esta reflexión, y si se quisiera hacer un enlace con el periodo republicano en Colombia, el fraile agustino Diego Francisco Padilla expresó: “el 20 de julio de 1810 estuvo entre los primeros patricios que formaron la junta de gobierno. [El fraile fue] denunciado por sus actividades en pro de la causa patriota, fue apresado y enviado a España" (Museo Nacional de Colombia, et al., 2002, p. 22). 
Pedro Pascasio Martínez nació en el departamento de Boyacá en la vereda Belén el 20 de octubre de 1807. Cuando Simón Bolívar conoció a Pedro, lo recibió como su ayudante por sus habilidades con el cuidado de los caballos. Pedro participó en las batallas del Pantano de Vargas y el Puente de Boyacá cuando tenía doce años en el Batallón Rifles. Pascasio estuvo en otras contiendas, no obstante, cuando se retiró, regresó a su ciudad natal. Falleció en 1885 con 78 años de edad (López, s.f.; Colombia aprende, s.f.a; Colombia aprende, s.f.b).

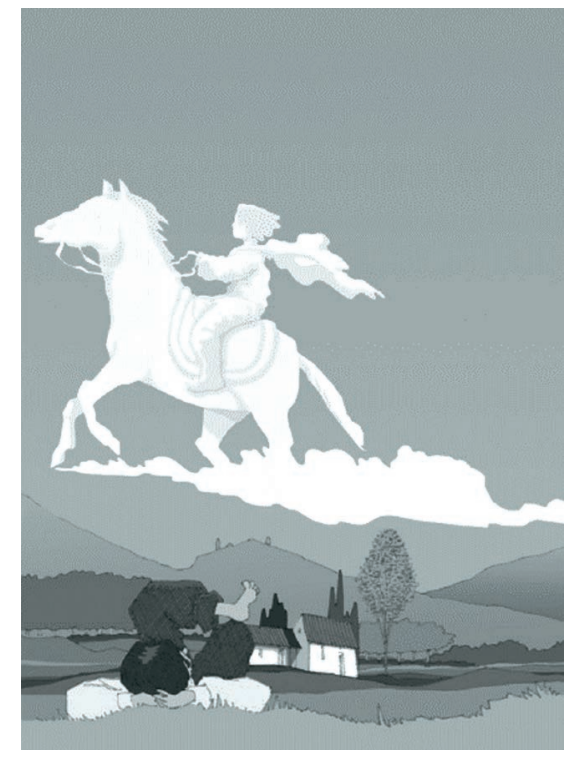

Figura 6. Pedro Pascasio Fuente: Díaz, C. \& Reyes, C. (2015). 
Se cuenta que en la noche del 7 de agosto, Pedro y el Negro José encontraron dos oficiales españoles escondidos en una cueva. Los dos soldados se enfrentaron a los oficiales y le quitaron la vida a uno de ellos. El coronel Barreiro, comandante general del ejército español, el único que sobrevivió, fue tomado como prisionero. Se cuenta que el general intentó sobornar a Pedro con monedas de oro a cambio de su libertad; sin embargo, Pedro se negó a aceptar y lo entregó preso personalmente a Simón Bolívar, quien posteriormente lo condecoró. El 31 de agosto de 1819, Simón Bolívar declaró en papel: “Ordenar a la dirección general para que disponga se le den cien pesos al soldado Pedro Pascasio Martínez como gratificación por haber aprehendido en Boyacá al General Barreiro" (Martínez, s.f.). Pascasio fue ascendido a Sargento, pero los 100 pesos nunca le fueron entregados (López, s.f.; Colombia aprende, s.f.a; Colombia aprende, s.f.b).

Este personaje fue dibujado por Roberto Páramo Tirado (figura 7), quien realizó copias de varios autores. La obra fue realizada a partir de una fotografía de Julio Racines. De igual manera, Páramo se destacó, principalmente, como paisajista de las primeras décadas del siglo XX (Museo Nacional de Colombia, s.f.). El dibujo está expuesto en el Museo Nacional de Colombia ${ }^{13}$, inaugurado en 1823 y ubicado en Bogotá en la localidad de Santa Fé y formó parte de la exposición temporal El reino frente al Rey: Reconquista, Pacificación, Restauración Nueva Granada (1815 - 1819).

${ }^{13}$ Otra pintura en óleo de

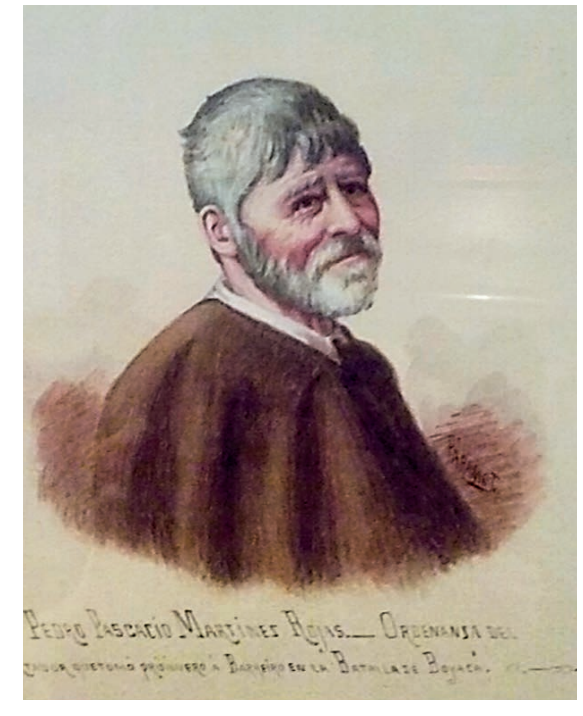

Figura 7. Pedro Pascasio Martínez, ordenanza de Simón Bolívar 1910. Acuarela sobre papel. Roberto Páramo Tirado. Museo Nacional de Colombia. 
Esta obra podría introducir un acontecimiento de la historia colombiana: la batalla de Boyacá, esta tuvo lugar en el Puente de Boyacá el 7 de agosto de 1819. Según Ocampo (2017), el ejercito de Simón Bolívar estaba conformado por 2850 combatientes; la división de la vanguardia tuvo 1000 soldados y estaba bajo el mando de Francisco de Paula Santander. El ejército realista tenía 2760 soldados y estaba liderado por el coronel José María Barreiro mientras la división de vanguardia, por el coronel Francisco Jiménez. Dos combates se desarrollaban al mismo tiempo, el primero en el puente - y alrededor del mismo -; el segundo, en la planicie hacia el camino de Samacá, municipio boyacense. El general Anzoátegui presionó las tropas realistas de Barreiro - capturado por el 'Negro' y Pascasio -, lo cual generó desorganización y fuga masiva; esto coadyuvó significativamente en la derrota de los realistas. Mientras tanto, el batallón de Santander cruzaba victorioso por el puente. La batalla de Boyacá fue imprescindible y motivó una nueva fuerza liderada por los independentistas, quienes también tuvieron triunfos en el Río de la Plata y Chile:

\section{Este triunfo patriota llevó a la culminación de la independencia de Colombia, permitió la organización y consolidación definitiva de la República de Colombia y facilitó el desarrollo y triunfo para las Campañas de Venezuela, Quito, Perú y Alto Perú, que llevaron a la independencia definitiva de las colonias americanas.}

Las aproximaciones a esta pieza podrían hacerse desde lo estético, lo histórico, lo artístico e inclusive, los ciclos etarios del ser humano. Adicionalmente, alrededor de la misma se podría trabajar el concepto de infancia y el rol de los niños y niñas en el periodo colonial en contraste con la actualidad. 

vista por todos los actores armados como una amenaza para sus planes de guerra y como una oportunidad para posicionarse (Centro Nacional de Memoria Histórica [CNMH], 2013).

En cuarto lugar, las influencias y presiones de las políticas internacionales, por ejemplo, EE.UU., el país que más ha influido en el conflicto armado colombiano, por su doctrina contrainsurgente y anticomunista durante la Guerra Fría y la lucha antiterrorista emprendida por este país en 2001, clausurando las posibilidades de negociación con la guerrilla; o la influencia de corrientes revolucionarias y socialistas en los grupos insurgentes, entre otros motivos. En quinto lugar, la fragmentación del Estado, en el ámbito institucional y territorial, así como los problemas de gobernabilidad, corrupción y falta de legitimidad (Centro Nacional de Memoria Histórica [CNMH], 2013). En sexto lugar, la justicia y la guerra: la impunidad, resultado de las distorsiones del conflicto. 
Finalmente, el narcotráfico se "conecta con el conflicto armado a principios de los ochenta como aliado, financiador y promotor de grupos paramilitares. Al mismo tiempo, se involucra como proveedor indirecto de recursos para las guerrillas" (Centro Nacional de Memoria Histórica [CNMH], 2013, p. 50). Está el caso del narcoterrorismo en el cartel de Medellín y Cali. Además, las AUC, que se han financiado por el narcotráfico, convirtiéndolas en una fuerza política.

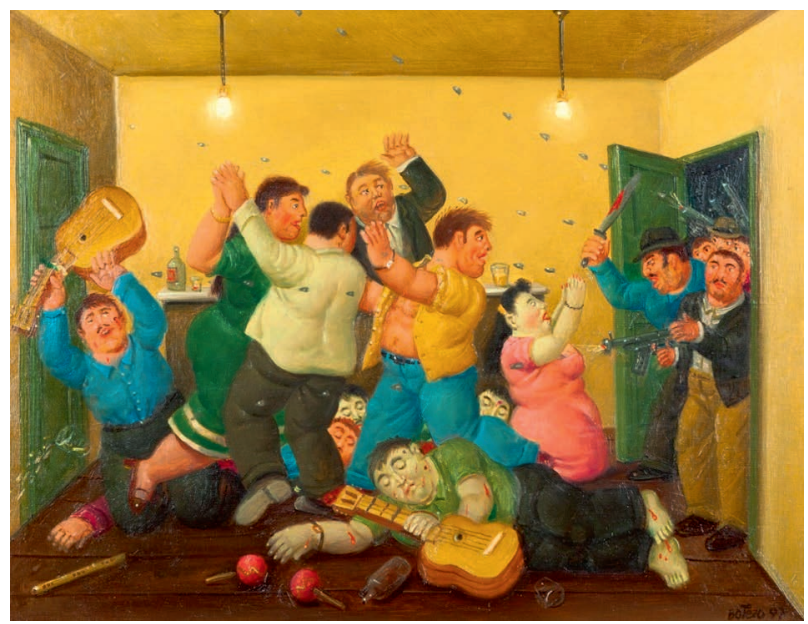

Figura 8. La Masacre de Mejor Esquina, 1977. Fernando Botero, Óleo sobre tela. Fuente; Museo Botero. Subgerencia Cultural del Banco de la República.

En esta investigación, el abordaje del conflicto armado en Colombia se desarrolla a partir del trabajo artístico de Fernando Botero Angulo sobre los grupos paramilitares. Botero nació en Medellín el 19 de abril de 1932, a sus 13 o 14 años se inició en la tradición acuarelista antioqueña. Es reconocido en el mundo como uno de los pintores colombianos más representativos, además de ser un destacado escultor. En el año 2000 donó parte de sus pinturas y de su colección de obras de artistas internacionales, dando paso a la apertura al Museo Botero, ubicado en Bogotá en la localidad de La Candelaria (González, 2006). Fernando Botero ha representado algunas realidades colombianas en sus obras; por esta razón, y en relación con el paramilitarismo y el conflicto armado, se seleccionó la obra Masacre de Mejor Esquina (figura 8), la cual escenifica la primera masacre paramilitar de la Costa Caribe. 
De acuerdo con Verdad Abierta (2012), en 1988, en el municipio de Buenavista, Córdoba en el caserío Mejor Esquina, un domingo de pascua un grupo de campesinos celebraba alrededor de las siete de la noche en la parcela de Teresa Martínez, hasta que un grupo armado irrumpió en la fiesta, "sin mediar palabra, los hombres arremetieron contra la población con sus fusiles y pistolas. Hombres, mujeres y niños cayeron sin entender el porqué de tanta sevicia. Quienes sobrevivieron, huyeron como pudieron. En total, asesinaron a 27 personas". Los campesinos fueron asesinados por el grupo paramilitar 'Los Magníficos', quienes acusaban a los asistentes de ser guerrilleros.

Fernando Botero pintó y representó un hecho que marcó la historia del país; esto posibilitó la relación entre memoria histórica y arte, con el objetivo de reconocer y comprender el conflicto armado colombiano; no obstante, esta no es la única obra por medio de la cual el artista hace alusión al conflicto. 


\section{Diálogos interdisciplinares e interinstitucionales}

Esta última sección contiene una propuesta para entidades educativas formales, no formales e informales y, además, presenta las conclusiones de este estudio. Una vez finalizado este recorrido y en línea con García (2007), se propone la siguiente estrategia a partir de la educación patrimonial. A continuación se definen las cinco fases de la estrategia, enmarcadas en el contexto de un espacio educativo:

- Fase I. Trabajemos desde lo que vemos: se exponen las cuatro obras, los participantes identifican el significado de estas, por ejemplo, el hecho histórico que representan, la identidad de los personajes, la época, el autor, entre otros. Lo más valioso de este ejercicio es mediar con los conocimientos que previamente poseen los participantes, para finalmente socializarlos.

- Fase II. Red de conexiones: se investigan y describen las cuatro obras a profundidad, en términos de su valor patrimonial, tanto para la comunidad de esa época como para la actual, su aporte hacia la construcción identitaria y de memoria histórica, sus características, el contexto en el cual fueron concebidas, su estado de conservación y la importancia de preservarlas. Si es posible, se sugiere gestionar la visita a los cuatro museos para conocer y contemplar las cuatro piezas; y para consultar con el personal especializado, por ejemplo: mediadores, curadores, museógrafos, centros de documentación, etc.

- Fase III. ¿Qué podemos hacer, aquí y ahora?: en esta sección, se dialoga alrededor de la relación interdisciplinar entre arte e historia y se tienen en cuenta las conexiones que surgen de esta discusión. Además, se proponen iniciativas conjuntas, con el objetivo de infundir valores alusivos preservar, proteger, disfrutar, difundir y finalmente, apropiarse de las cuatro obras. Adicionalmente, se identifican los recursos necesarios para llevar a cabo las estrategias y/o propuestas pedagógicas.

- Fase IV. ¿Qué estamos esperando? ¡Luego es tarde! Se organizan en grupos y se ejecutan actividades, siempre y cuando sea con el acompañamiento de quienes estén liderando la actividad.

- Fase V. Saber lo que hicimos. Si no evaluamos no lo sabremos: se evalúan las acciones y el impacto de las intervenciones. También, se divulgarán los resultados y se propone replicarlos con familiares, amigos o conocidos de los participantes. 
La estrategia anteriormente descrita, pretende involucrar directamente a los participantes con los cuatro objetos, identificando así su valor patrimonial. El ejercicio propende a instaurar relaciones interdisciplinares, permitiendo abordar hechos históricos del país a través de la observación, investigación y análisis de las cuatro obras. Reconociendo, además, la evolución del arte y la representación de eventos históricos. En línea con DeCarli (2018), al patrimonio se le está asignando una función en donde los participantes tienen un rol activo (enfoque constructivista), con el cual conciben y desarrollan iniciativas; esto multiplica el impacto de la intervención, pues entre más se replique, mayor será la conciencia comunitaria sobre el reconocimiento, preservación y difusión del patrimonio cultural.

Tal como enuncia el ILAM (2018), es esencial y urgente considerar una definición de patrimonio cultural menos descriptiva y más funcional. Parte de la población aún no es consciente de los vínculos con sus patrimonios, los cuales, a su vez, tienen distintos valores y percepciones; por ello, es esencial asignarles un uso o, por lo menos, darles un sentido.

Es común que los museos recurran a lenguajes poco accesibles no solo desde la curaduría sino también desde la museografía, e incluso en el área educativa. Esto entorpece las interacciones entre las exhibiciones y los públicos. Una de las ventajas de la Educación Patrimonial con enfoque constructivista son las alternativas que ofrece. Si bien no es un proceso fácil, es enriquecedor para ambas partes. Teixeira (2006) habla de aceptar "rupturas y los nuevos lenguajes creadores, como lenguajes culturales actuales y dinámicos". Los museos deben estar al tanto de la realidad sociocultural, muchas exhibiciones carecen de la relación pasado-presente, esto podría dificultar el establecer y fortalecer vínculos con los patrimonios.

La EP suscita el reconocimiento, conservación, preservación, difusión, disfrute y activación del patrimonio cultural, lo cual instaura y fortalece los valores, la memoria, el sentido de pertenencia y la identidad cultural de una comunidad; esto habla precisamente de la asignación de una función social al patrimonio preservado por los museos. No es únicamente un patrimonio dispuesto para ser observado, es la puesta en valor del patrimonio cultural a partir de estrategias y materiales pedagógicos.

La interdisciplinariedad es una construcción colectiva porque propicia la lectura de obras, hechos históricos y técnicas artísticas desde otras perspectivas, además, demanda la composición de equipos con profesionales o expertos de diferentes áreas del conocimiento. No se trata de decir cuál perspectiva es la más o menos adecuada, sino de nutrirlas entre sí. Los públicos tienen una amplia gama de gustos 
y preferencias y el ofrecerles más alternativas no sólo posibilita el aumento del número de visitantes, sino también genera otras interacciones, probablemente más significativas. Los bienes culturales, en sí mismos, integran numerosos conocimientos y a su vez son dinámicos y cambiantes. Esta es una oportunidad para encaminarse hacia otras lecturas.

Incluir otros lenguajes es una apuesta hacia el pensamiento crítico, ya que se cuestionan o enriquecen otros discursos. Sin embargo, estas lecturas interdisciplinares tienen sus límites, por los recursos disponibles, por la cultura y flexibilidad institucional, por la dificultad de abordar cierta temática a partir de una pieza, por la disposición del público, por el alcance y por la pertinencia de los vínculos establecidos; $\mathrm{y}$ al mismo tiempo son subjetivas, porque tanto las piezas como los enlaces entre ellas están sujetos a la interpretación de uno o varios sujetos. Esto hace necesario un alto nivel de conocimiento y preparación, pero principalmente, en reflexionar sobre la intención de la propuesta educativa.

La interinstitucionalidad facilita la interacción entre museos, los cuales podrían pensar en colecciones o actividades colegiadas, que favorezcan correlaciones entre obras, temáticas, exposiciones o salas. También es imprescindible que los museos intercambien sus buenas prácticas y gestionen sus públicos en colectivo. Para nadie es un secreto que el sector cultural y, particularmente, los museos, tienen dificultades para captar audiencias.

En términos de consumo cultural, los museos tienen un desafío enorme. En pocos museos se concentran grandes cantidades de asistentes e incluso hay poca frecuencia en las visitas. En estos aspectos se evidencia la falta de financiación, la poca visibilidad y la percepción del sector. Además, si se habla de accesibilidad, las estrategias educativas desde una perspectiva inclusiva, no se pueden pasar por alto. Frecuentemente, se escucha que el patrimonio es de todos; sin embargo, en la actualidad son evidentes las barreras entre las comunidades y los patrimonios. En algunos casos, por estratificación social; en otros, por la complejidad del lenguaje, por la ideología, por intereses particulares, por discapacidades, entre otros. Sería interesante preguntarse, ¿qué relación existe entre los referentes identitarios y el consumo cultural? ¿Qué responsabilidades tienen las instituciones? ¿Qué responsabilidades tienen las comunidades?

Esta es apenas una de las innumerables propuestas -entre muchas otras que se han hecho y se siguen haciendo- que podrían interconectar espacios y/o iniciativas culturales con lecturas interdisciplinares. Es posible acercarse al patrimonio cultural desde múltiples nociones, percepciones e interpretaciones. La Figura Antropomorfa podría conectarse con algunas de las diez temáticas de la nueva sala del Museo 
Nacional de Colombia, Tiempo sin olvido ${ }^{14}$. En esta exposición se tomaron como referente diez ejes temáticos alrededor de los cuales se concibió esta muestra: producir: el lugar de los alimentos; habitar: la morada de los vínculos; trabajar: los oficios cotidianos; hilar: el tejido de la sociedad; intercambiar: el movimiento de los objetos; representar: el cuerpo como símbolo; controlar: las formas del poder; luchar: las confrontaciones por recursos e ideas; celebrar: los rituales y ceremonias; y morir: espacios del más allá (Museo Nacional de Colombia \& Instituto Colombiano de Antropología e Historia, 2018). La obra San Agustín posibilita reinterpretar lo colonial como un choque entre culturas que moldea un nuevo mundo, más allá de víctimas y victimarios, visibilizar el mestizaje cultural, consiguiendo así, leer la colonia en clave de la transformación de dos mundos en conflicto, en donde transitaron hombres, ideas, productos e idiomas (Cruz, 2017). De igual manera, la imagen colonial podría ser otra lectura en términos de "mostrar su especificidad, sus antecedentes y las formas de construcción, imposición y transformación de sus funciones en el territorio [...]" (Toquica, s.f., p. 1).

La pintura de Pedro Pascasio permitiría indagar acerca de cómo vivían los niños en el período republicano, considerando que la niñez es un término mucho más actual. ¿Qué implica la participación de un niño de 12 años en una guerra en 1819 y en 2019? Finalmente, la Masacre de Mejor Esquina, que además del narcotráfico podría servir para introducir la historia del conflicto armado colombiano. Estas asociaciones pretenden incitar en el lector la inquietud de que una sola pieza es un mar de posibilidades en términos de lecturas, interpretaciones y conexiones. La educación patrimonial desde una perspectiva constructivista, interdisciplinar e interinstitucional es una oportunidad para tejer vínculos, para cuestionar, para enriquecer, para reconocer, para preservar y difundir el patrimonio cultural, para problematizar y nutrir los referentes identitarios. 


\section{REFERENCIAS BIBLIOGRÁFICAS}

Alfageme, M. \& Martínez, N. (2007). Un modelo pedagógico en un contexto no formal: el Museo. Archivos Analíticos de Políticas Educativas, 15(21), 1-19. Recuperado de http://www.redalyc.org/articulo. oa?id=275020546021

Arango, J. (1979). Cerámica precolombina. Bogotá: Plaza \& Janes Editores.

Banco de la República. (Junio de 2001). La casa de las aulas. Recuperado de http://www.banrepcultural.org/ blaavirtual/revistas/credencial/junio2001/lacasa.htm.

Botero, F. (1997). Masacre de mejor esquina [Pintura]. Colombia: Museo Botero. Recuperado de http://banrepcultural.org/coleccion-de-arte-banco-de-la-republica/obra/masacre-de-mejor-esquina

Centro Nacional de Memoria Histórica (2013). ¡Basta ya! Colombia: Memorias de Guerra y Dignidad. Resumen. Bogotá: Imprenta Nacional de Colombia.

Congreso de Colombia. (12 de marzo de 2008). Ley general de Cultura. [Ley 1185 de 2008]. DO: 46.929.

Colombia Aprende. (s.f.a). Niños de carne y hueso. Recuperado de http://www.colombiaaprende.edu.co/ html/home/1592/article-228420.html

Colombia Aprende. (s.f.b). Preguntándole al historiador. Recuperado de http://www.colombiaaprende.edu. $\mathrm{co} / \mathrm{html} / \mathrm{home} / 1592 /$ article-228420.html

Cruz, J. (2017). Descubrimiento y conquista, escenarios de una transformación global. Reflexiones sobre el amanecer de "lo colonial" en la América española. Meridional, Revista Chilena de Estudios Latinoamericanos. 8, 13-44. Recuperado de http://www.filosofia.uchile.cl/documentos/descarga-revistameridional-n-8-pdf-16-mb_132637_0_3330.pdf

DeCarli, G. (2018). Fundación ILAM. El Patrimonio: su definición, gestión y uso social. Recuperado de https:// ilamdocs.org/documento/3505/

Díaz, C. \& Reyes, C. (2015). Pedro Pascasio, el pequeño prócer. Bogotá: Distribuidora y Editora Richmond S.A. 
Durán, P. (2013). Reflexiones en torno al valor pedagógico del constructivismo. Ideas y valores, 43(155), 171-190. Recuperado de http://www.scielo.org.co/pdf/idval/v63n155/v63n155a08.pdf

Fondo de Promoción de la Cultura del Banco Popular. (1990). Arte de la tierra: Quimbayas. Bogotá: Editorial Presencia.

Fondo de Promoción de la Cultura del Banco Popular. (1993). La Casa del Marqués de San Jorge. Bogotá: Litografía Arco.

Franco, L. (2017). Tensiones coloniales en las narrativas sobre el pasado de Tierradentro (Cauca, Colombia). Maguaré, 31(2), 129 - 163. Recuperado de https://revistas.unal.edu.co/index.php/maguare/article/ view/71536

García, Z. (2007). Estrategias educativas para la valoración del patrimonio cultural en la educación básica en Venezuela. EDUCRE, 39, 673-681.

González, N. (2006). Colombia en la pintura de Fernando Botero. Barcelona. (Tesis doctoral). Universidad Politécnica de Catalunya, Barcelona, Cataluña, España.

Instituto Distrital de las Artes [IDARTES]. (2015). Breviario de la Paz. Bogotá, Colombia.

Instituto Distrital de Patrimonio Cultural (IDPC). (s.f.). Nuestro Patrimonio. Recuperado de http://idpc. gov.co/nuestro-patrimonio-2/.

López, M. (s.f.). Pequeños Libertadores. Historia Hoy: Aprendiendo con el Bicentenario de la Independencia. 200 años, 200 preguntas. Recuperado de http://www.colombiaaprende.edu.co/html/productos/1685/ articles-240822_Respuesta_1097.pdf

Martínez, P. (s.f.). Centro de estudios históricos del ejército. Recuperado de http://www.ejercito.mil. $\mathrm{co} /$ idcategoria $=210809$.

Molano, O. L. (2007). Identidad cultural un concepto que evoluciona. Ópera, 7, 69-84. 
Morán, J. (2017). Propuesta Educativa dentro de la gestión del Patrimonio Cultural para la formación de Agentes de Cambio. Trabajo presentado en 2. ${ }^{\circ}$ Congreso Latinoamericano de Gestión Cultural de la Red Latinoamericana de Gestores Culturales, Cali, Colombia.

Museo Arqueológico [MUSA]. (2006). Arte de la tierra: Quimbayas. Bogotá: AGT Asociados Ltda.

Museo Nacional de Colombia, et al. (2002). Historia \& Imágenes: Los Agustinos en Colombia, 400 años. Bogotá: Grupo OP S.A.

Museo Nacional de Colombia \& Instituto Colombiano de Antropología e Historia (2018). Sala 3 Tiempo sin olvido: diálogos desde el mundo prehispánico. Curaduría de Arqueología.

Museo Nacional de Colombia. (s.f.). Software Colecciones colombianas, catálogo de la colección del Museo Nacional de Colombia: Bogotá.

Ocampo J. (2017). Historia básica de Colombia. Bogotá: Editorial Delfín S.A.S.

Organización de las Naciones Unidas para la Educación, la Ciencia y la Cultura [UNESCO]. (Julio a Agosto de 1982). Declaración de México sobre las Políticas Culturales. México D.F., México.

Páramo, R. (1910). Pedro Pascasio Martínez, ordenanza de Simón Bolívar [Dibujo, acuarela]. Colombia: Museo Nacional de Colombia.

Pizano, O., Zuluaga E. \& Quiroga, P. (2010). La gestión del patrimonio cultural: perspectivas de actuación desde la academia. Bogotá: Editorial Pontificia Universidad Javeriana.

Rojas, L. (1979). Manual de Arqueología Colombiana. Bogotá: Carlos Valencia Editores.

Secretaría Distrital de Cultura, Recreación y Deporte (SCRD). (2016). Estadísticas de Bienes de Interés Cultural en Bogotá 2016. Recuperado de http://sispru.scrd.gov.co/siscred/sites/default/files/Bolet\%C3\%ADn\%20 No.\%2020\%20Bienes\%20de\%20Inter\%C3\%A9s\%20Cultural.pdf

Secretaría de Cultura, Recreación y Deporte (SCRD) - Observatorio de Culturas. (2016). Encuesta Bienal de Culturas 2015. Recuperado de http://www.culturarecreacionydeporte.gov.co/observatorio/ENCUESTABIENAL2015/EBC2015_PRES.html 
Teixeira, S. (2006). Educación Patrimonial: Alfabetización Cultural para la Ciudadanía. Estudios pedagógicos (Valdivia), 32(2), 133-145. Recuperado de https://dx.doi.org/10.4067/S0718-07052006000200008

Therrien, M. (1993). Preservación del Patrimonio Cultural Nacional. Bogotá: Instituto Colombiano de Antropología.

Toquica, C., et al. (2008). El oficio del pintor: nuevas miradas de la obra de Gregorio Vásquez. Bogotá: Ministerio de Cultura.

Toquica, C. (s.f.). Entre el infierno y la salvación: el territorio vacío. Aproximaciones a la imagen colonial neogranadina. Bogotá: Museo Colonial y Ministerio de Cultura.

UNIMINUTO (s.f.). Mac al cuadrado: Una experiencia pedagógica a través del celular. Recuperado de http://www.uniminuto.edu/inicio?p_p_id=101\&p_p_lifecycle=0\&p_p_state=maximized\&p_p_ mode=view\&_101_struts_action=\%2Fasset_publisher\%2Fview_content\&_101_returnToFullPage URL=http\%3A\%2F\%2Fwww.uniminuto.edu\%2Fja\%2Finicio\%3Fp_auth\%3DDwCFd7vZ\%26p_p_ id\%3D3\%26p_p_lifecycle\%3D1\%26p_p_state\%3Dnormal\%26p_p_state_rcv\%3D1\&_101_ assetEntryId=1610681\&_101_type=content\&_101_groupId=14444490\&_101_urlTitle=mac-al-cuadradouna-experiencia-pedagogica-a-traves-del-celular\&inheritRedirect=true

Verdad abierta. (26 de abril de 2012). Lo que la justicia no quiso ver en la Masacre de La Mejor Esquina. Recuperado de http://www.verdadabierta.com/component/content/article/83-juicios/3994-lo-que-lajusticia-no-quiso-ver-en-el-caso-de-la-mejor-esquina/. 